\title{
The Influence of Sintering Conditions on the Inkjet Printed Paths Resistance
}

\author{
Grzegorz Tomaszewski, Tadeusz Wałach, Jerzy Potencki, and Mariusz Pilecki
}

\begin{abstract}
The sintering of elements performed with the inkjet printing technique is one of the stages of flexible printed circuit manufacturing process. It is a crucial factor to determining the printed paths conductivity playing often an important role in the printed circuit. In this paper the study of the influence of thermal sintering conditions (temperature, time) on the resistance of paths made with inkjet printing on flexible substrates by using two electrically conductive inks was presented. The results of the investigations show that the sintering temperature is the main factor determining the paths resistance. Therefore, in some applications the sintering temperature higher than the one specified by the ink manufacturer can be used to decrease the paths resistance and to improve some circuit parameters. However, it should be noticed that the effective resistance decrease occurs only up to a certain temperature due to the appearance cracks in the printed paths.
\end{abstract}

Keywords-sintering, inkjet printing, printed electronics, flexible electronics, nanosilver ink

\section{INTRODUCTION}

I recent years, attempts to implement technologies which until now were unnoticeable in the area of electronic industry are observed more often. An example of a promising technology is the inkjet printing, until recently used only in the printing industry. This non-contact printing technique is a digital technique with a relatively high precision and can be used in the electronic industry both for prototyping and manufacturing microstructures to form contact pads, conducting paths or more complex elements [1-5].The inkjet printing technique requires the use of special liquids called inks which should be true solutions with a low viscosity. These inks should enable one to create conductive paths. Usually the inks are suspensions with a filler in form of noble metal nanoparticles and with additional components facilitating the printing and affecting the properties of printed layers [6,7]. After printing the pattern on the substrate, the treatment procedure called sintering is required to achieve appropriate

This work was supported in part by the Polish National Centre for Research and Development (NCBR) under Grant No. PBS1/A3/3/2012. The work was developed by using the equipment purchased in the Operational Program Development of Eastern Poland 2007-2013 of the Priority Axis I Modern Economics of Activity I.3 Supporting Innovation under Grant No. POPW.01.03.00-18-012/09-00 and the Program of Development of Podkarpacie Province of The European Regional Development Fund under Grant No.UDA-RPPK.01.03.00-18-003/10-00.

Grzegorz Tomaszewski, Tadeusz Wałach, Jerzy Potencki and Mariusz Pilecki are with the Rzeszów University of Technology, al. Powstańców Warszawy 12, 35-959 Rzeszów, Poland (e-mail: gtom@prz.edu.pl, tawal@prz.edu.pl,jurpot@prz.edu.pl,mpilecki@prz.edu.pl). electrical properties of the printed layers [8]. The processes occurring during this stage have a significant impact on the resistivity of the material forming the printed paths. One of the most frequently used sintering methods is the thermal treatment of material. It is known that both the temperature and the time of such treatment is crucial in sintering process $[9,10]$. Proper conditions of this process enable one to obtain desired characteristics of the printed patterns, which is often important from the application point of view.

\section{SINTERING}

Considering the rheology requirements for the inks with nanoparticles of metals are similar to the conventional printing inks. Additionally, the conductive inks containing the functional material should be compatible with the substrate material and able to create the low-resistivity layers. The size of the metal particles (usually silver) being the ink is very small (a few nanometers) and therefore these particles must be protected from aggregation to obtain an even spatial distribution of them and to prevent the printer nozzles from the clogging effect. It can be reached by chemical synthesis and creating the encapsulated metal core by a thin polymer shell for each particle. For this reason, although the percentage of the metal particles with a good conductivity in the ink is high, the printed patterns do not conduct an electric current. Therefore, functionalization of the printed layers requires removing the insulating shells and forming the stable joints between the metal particles. The additional treatment process of creating these joints is called sintering. In this process the metal nanoparticles are usually welded under the influence of heat at a temperature below the melting point of the pure metal. This process is one of the last steps in the flexible circuit fabrication. On the one hand, the sintering removes all organic additives forming the particles shells, and on the other hand, it creates joints between the metal particles as a result of their crystallization $[6,8,11]$. The sintering process can be divided into 3 stages which are strongly connected with the conditions of technological process - temperature and time. In the first stage, the treated printed layer has a high resistance (in the order of $M \Omega$ ). The resistance value depends significantly on the process temperature (the higher temperature, the shorter time of the first stage). In the second stage (this stage is important to obtain a proper conductivity), the removal of the insulating protective particles shells and a dynamic change of the resistance (it is reduced very quickly - to the order of $\Omega$ ) can be observed. The time of this stage (about tens of minutes) depends on the process temperature (this time is shorter for a higher temperature). In the third stage of sintering there are small changes in the resistance (in the order of $\Omega$ ) for a long time (a few hours) 
caused by the particles recrystallization and formation of larger nanosized structures $[10,12]$. For many commercially available inks with silver nanoparticles having a size up a dozen or so nanometers, the third stage starts within 60 minutes when the process temperature is higher than $200^{\circ} \mathrm{C}$ [6]. There are also nanosilver inks with a reduced sintering temperature - below $150^{\circ} \mathrm{C}[13,14]$. From the application point of view, the sintering conditions play an important role because they determine the conductivity of the printed patterns and the applicability of particular substrates. The thermal treatment of the printed patterns is the most common sintering method. For some inks, however, a high temperature required during the sintering process excludes some substrates which are very attractive in low-cost production from using [15]. Therefore, the conventional thermal sintering of nanoparticles is sometimes replaced by another less common techniques like plasma, microwave, laser, electrical or chemical treatment $[8,16,17]$.

\section{EXPERIMENT}

Tested patterns in the form of paths (Fig. 1a) with a design width $\mathrm{d}=0.5 \mathrm{~mm}$ and length $\mathrm{l}=100 \mathrm{~mm}$ (200 squares) were printed on flexible substrates using a PixDro LP50 printer with a Spectra SE-128 AA print head. In the experiment two kind of flexible substrates were used: polyimide (PI - two sheets signed as $\mathrm{A}$ and $\mathrm{B}$ ) and polyethylene terephthalate (PET).

Just before the printing process the substrates went through a special cleaning procedure in order to remove any organic and inorganic contaminations which could have an adverse

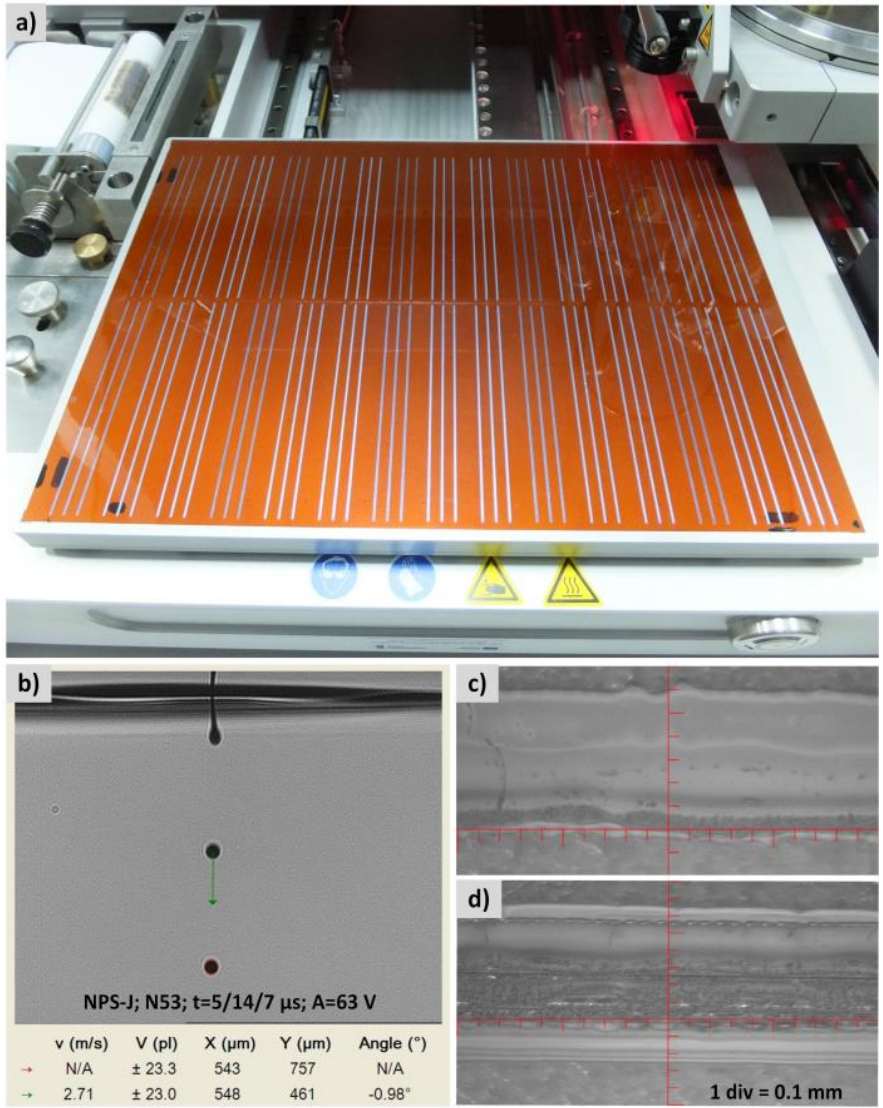

Fig. 1. Tested paths on PI substrate after printing process (a), ink drops ejected by printed nozzle (b), image of semi dry 1-layer (c) and 3-layer (d) path effect on the path morphology or ink adhesion. Taking into account the previously conducted studies [18] in which the problems in the ink spread on some substrates were observed, before the printing process the PET substrate was undergone an additional treatment in order to obtain a more hydrophobic surface and to minimize the ink spreading. In each case the ink spread was limited by maintaining the substrate at a temperature of $60^{\circ} \mathrm{C}$ to ensure faster solvent evaporation. The paths were printed using two commercially available nanosilver inks: NPS-J for the PI substrate and NPS-JL for the PET one. Only one nozzle (N53) was used in the process. The volume of ejected droplets was about $23 \mathrm{pL}$. The control settings of the nozzle piezoelectric actuator were $5 / 14 / 7 \mu \mathrm{s}$ for the rise/duration/fall time of the stimulation pulse, respectively. The pulse amplitude determining the volume of drops was $63 \mathrm{~V}$ (Fig. 1b). The paths were printed using the one-way printer mode with a speed of $300 \mathrm{~mm} / \mathrm{s}$ and a resolution of $400 \mathrm{dpi}$. Thirty sets of three paths with a different number of layers $(1,2,3)$ were printed on each substrate sheet and subsequently subjected to the heat treatment. About 240 samples (180 for the PI sheets and 60 for the PET sheets) in total were examined. In determining the sintering conditions (temperature and time) the manufacturer's recommendations were taken into account. According to them, a considerable decrease in the resistivity is observed in a temperature range from $180^{\circ} \mathrm{C}$ to $200^{\circ} \mathrm{C}$ and from $125^{\circ} \mathrm{C}$ to $150^{\circ} \mathrm{C}$ for the NPS-J and NPS-JL ink, respectively. For the higher temperatures the resistivity is practically constant [14].The sintering conditions proposed by the manufacturers are as follows: the temperature about $220^{\circ} \mathrm{C}$ for NPS-J and $130-150^{\circ} \mathrm{C}$ for NPS-JL, the treatment time about $1 \mathrm{~h}$ [14]. In this study the thermal treatment of the NPS-J ink and the NPS-JL ink was planned in the temperature range of 200$280^{\circ} \mathrm{C}$ and $100-200^{\circ} \mathrm{C}$, respectively, with the temperature step of $20^{\circ} \mathrm{C}$, for two treatment times of $1 \mathrm{~h}$ and $2 \mathrm{~h}$. Additionally, for the temperature of $220^{\circ} \mathrm{C}$ the influence of the time on the resistance of the path printed by the NPS-J ink was examined. The treatment time was changed from $0.5 \mathrm{~h}$ to $2.5 \mathrm{~h}$ with the $0.5 \mathrm{~h}$ step in this investigation. After the thermal treatment processes the printed paths were inspected under the microscope and the paths width was measured. Some paths were also inspected during the printing process (Fig. 1c, d).

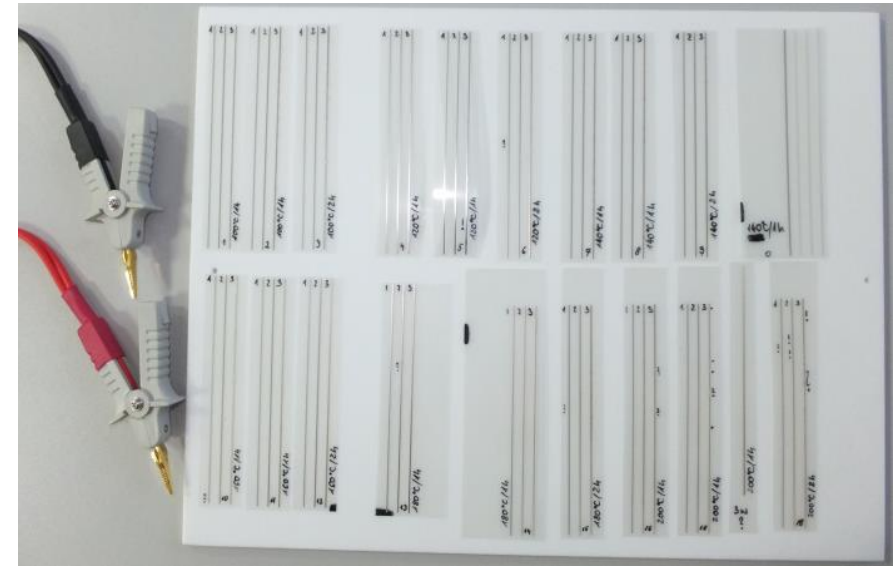

Fig. 2. Cut samples subjected to resistance measurements 
On the final stage of the experiment the resistance of the printed paths (Fig. 2) was measured using the four-wire method (DMM4020 multimeter was used) and then the sheet resistance of the paths was calculated.

\section{RESULTS}

In most cases, the printed paths evaluated microscopically have regular shapes and are uniformly filled (Fig. 3a). Only in some cases narrowings (Fig. 3b) or unfilled subareas (Fig. 3c) in the paths can be observed. These paths were not taken into account in the resistance calculations. Since the spread of the ink on the untreated PET was strongly irregular, the paths printed on this substrate were excluded from the studies. In case of the 3-layer paths local widenings can be quite often found (Fig. 3d). For a high sintering temperature crosswise (Fig. 3e) or - more often - lengthwise cracks (Fig. 3f) occur in some subareas of the 2- and 3-layer paths. Some cracks look like small craters (Fig. $3 f-$ example on the right).

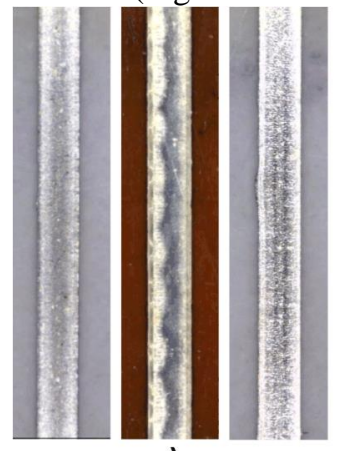

a)

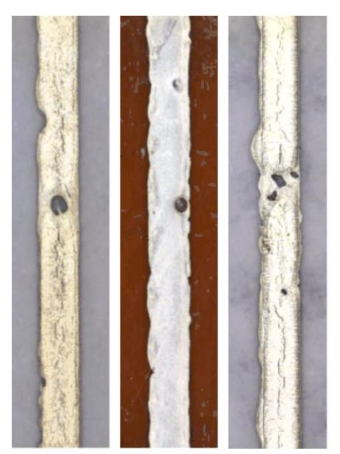

c)

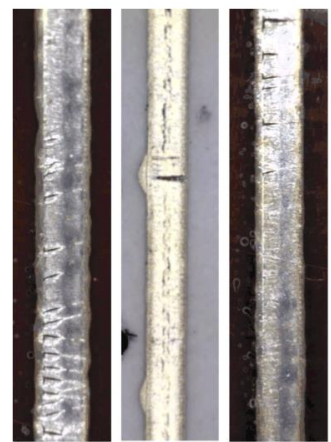

e)

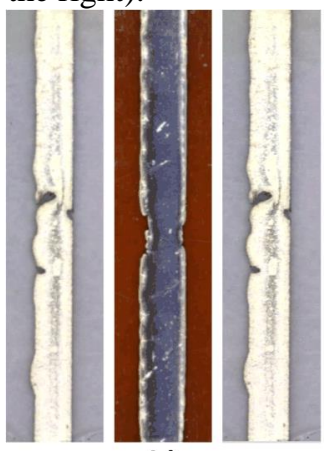

b)

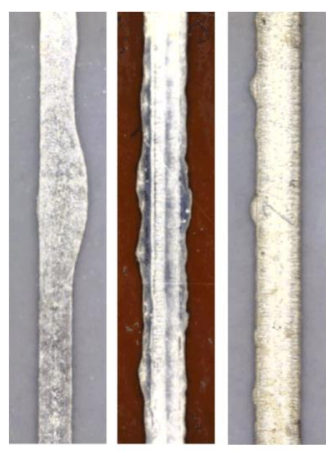

d)

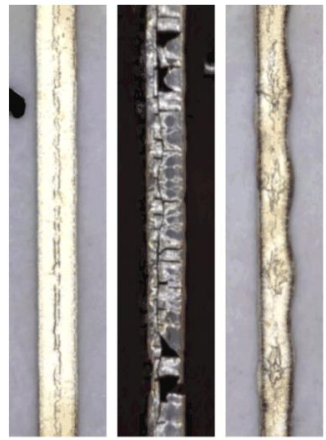

f)
Fig. 3. Images of printed paths with: regular shapes (a), narrowings (b), unfilled subareas (c), widenings (d), crosswise cracks (e), lengthwise and crater cracks (f)
The described defects concerns mainly the paths printed on the PET substrate. The paths with the resistances differing significantly from the others due to the defects were excluded from the average resistance calculations. The average width of the paths printed on the PET substrate with the NPS-JL ink is about $0.60 \mathrm{~mm}$ for the 1- or 2-layer paths and $0.64 \mathrm{~mm}$ for the 3-layer paths. In case of the NPS-J ink and the PI sheet signed as $\mathrm{A}$ (PI-A) these values are $0.70 \mathrm{~mm}, 0.71 \mathrm{~mm}$ and $0.73 \mathrm{~mm}$, and for the NPS-J ink and the PI sheet signed as B (PI-B): $0.77 \mathrm{~mm}, 0.78 \mathrm{~mm}, 0.79 \mathrm{~mm}$, respectively. The comparison of obtained values with the designed value of $0.50 \mathrm{~mm}$ shows that the ink spread on the PET substrate is much smaller than on the PI one. The differences confirm that the PET substrate has greater hydrophobicity. As an objective measure of path properties, the sheet resistance was assumed. This is a typical parameter that characterizes multilayer elements produced using different technologies and is defined as the resistivity $\rho$ normalized in relation to the thickness $h$ :

$$
R_{S}=\frac{\rho}{h}=R \frac{w}{l}
$$

The average of resistance $R_{S}$ was calculated for a few paths and for a great number of squares (ratio 1/w close to 200). For each path the resistance $R$, the average width $w$ and length $l$ (exactly, $l$ denotes the distance between the measuring probes) were measured. As a scatter of results the mean absolute deviation was assumed. For the paths printed on the PI-A, PI-B and PET substrates the deviations of $1.2 \Omega, 0.9 \Omega, 0.5 \Omega$ were obtained, respectively. The sheet resistance as a function of the temperature is shown in Fig. 4. A number of the path layers and the sintering time expressed in hours are indicated in the legend. The first two considered cases concern the paths printed with the NPS-J ink on the two PI sheets. The examinations for the PI-A sheet (Fig. 4a) were carried out in a temperature range narrower than for the PI-B sheet (Fig. 4b). The comparison of the NPS-J ink specification with the curves in Fig. 4b shows that the resistance decrease obtained for the sintering temperature increase from $200^{\circ} \mathrm{C}$ to $220^{\circ} \mathrm{C}$ is significantly larger than the one specified by the ink manufacturer (for all path thicknesses). In case of the 1-layer paths sintered in time of 1 hour the resistance decreases up to the temperature of $280^{\circ} \mathrm{C}$. For the 2- and 3-layer paths the resistance decreases distinctly only up to the temperature of $240^{\circ} \mathrm{C}$. For the temperature of $260^{\circ} \mathrm{C}$ the resistance decreases slightly (in three cases) or it does not change (in one case), but for the temperature of $280^{\circ} \mathrm{C}$ the resistance increases. In three cases this change is very distinct and is an effect of microcracks. In case of the 2- or 3-layer paths the sintering time has an insignificant influence on the sheet resistance. This time has a bit greater influence on the resistance changes for the 1-layer paths, but random nature of these changes indicates a greater influence of the path printing defects on the resistance than the sintering time. An another analysis shows that the probability diminishing the influence of the printing defects grows rapidly with the number of printed layers. In case of the PET substrate and the NPS-JL ink (Fig. 4c), the sheet resistance decreases significantly for the temperature above $150^{\circ} \mathrm{C}$, but according to the ink manufacturer datasheet tendency is particularly visible for the 1-layer paths for which the decrease occurs up to the temperature of $200^{\circ} \mathrm{C}$. For the 2- and 3-layer paths sintered 

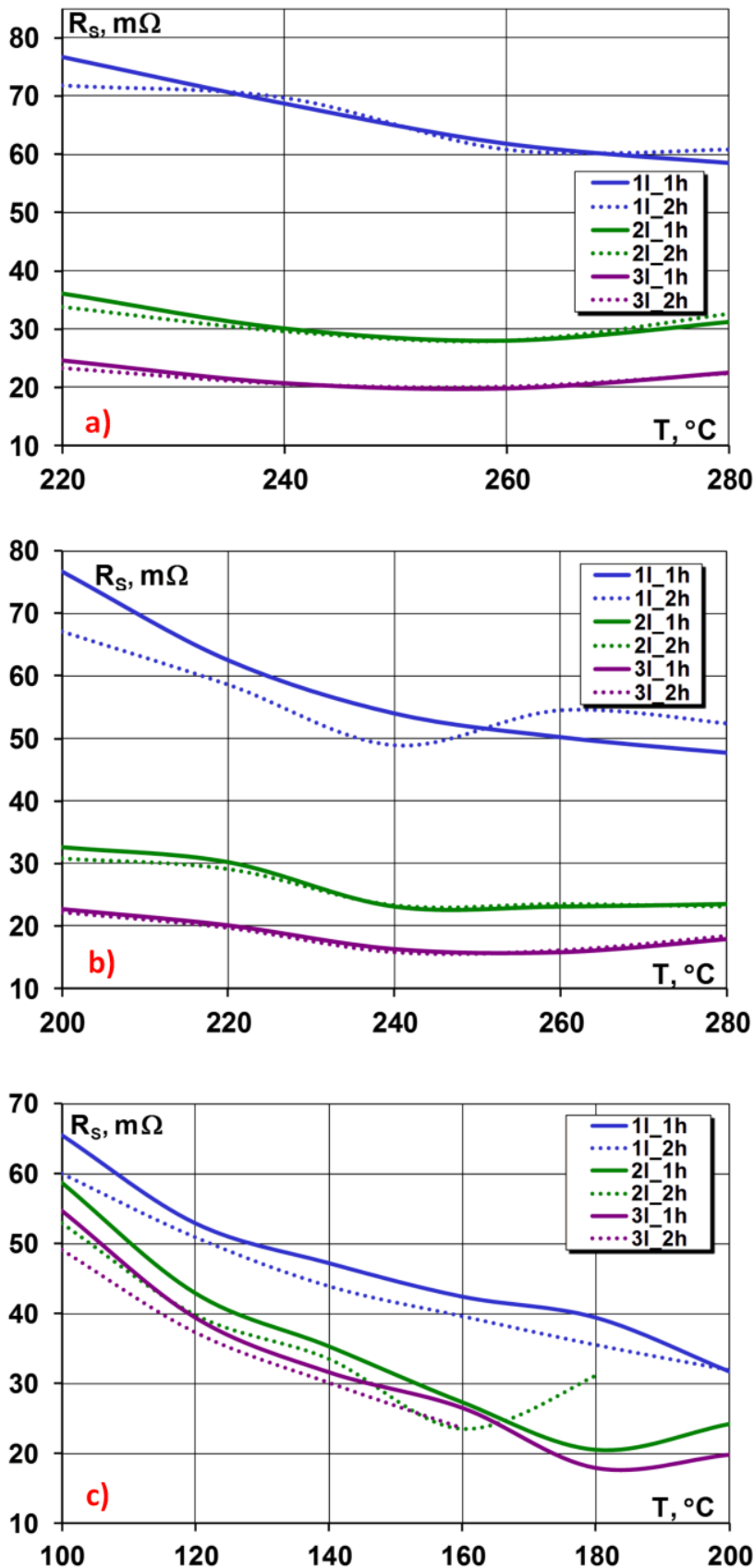

Fig. 4. Sheet resistance vs. sintering temperature (a: PI - sheet A, NPS-J ink; b: PI - sheet B, NPS-J ink; c: PET, NPS-JL ink)

for 1 hour the resistance increases slightly at the temperature of $200^{\circ} \mathrm{C}$, what is caused by the appearance of microcracks. The large resistance increase caused by this effect is already observed for the temperature of $180^{\circ} \mathrm{C}$ for the 2-layer paths sintered for 2 hours.

Printing defects in the 3-layer paths designed for the sinterization at a temperature above $160^{\circ} \mathrm{C}$ for 2 hours excluded these paths from the examinations. The influence of the sintering time on the paths resistance in a wider range of the time for the polyimide substrates was shown in Fig. 5. An analysis of the obtained results leads to the conclusion that
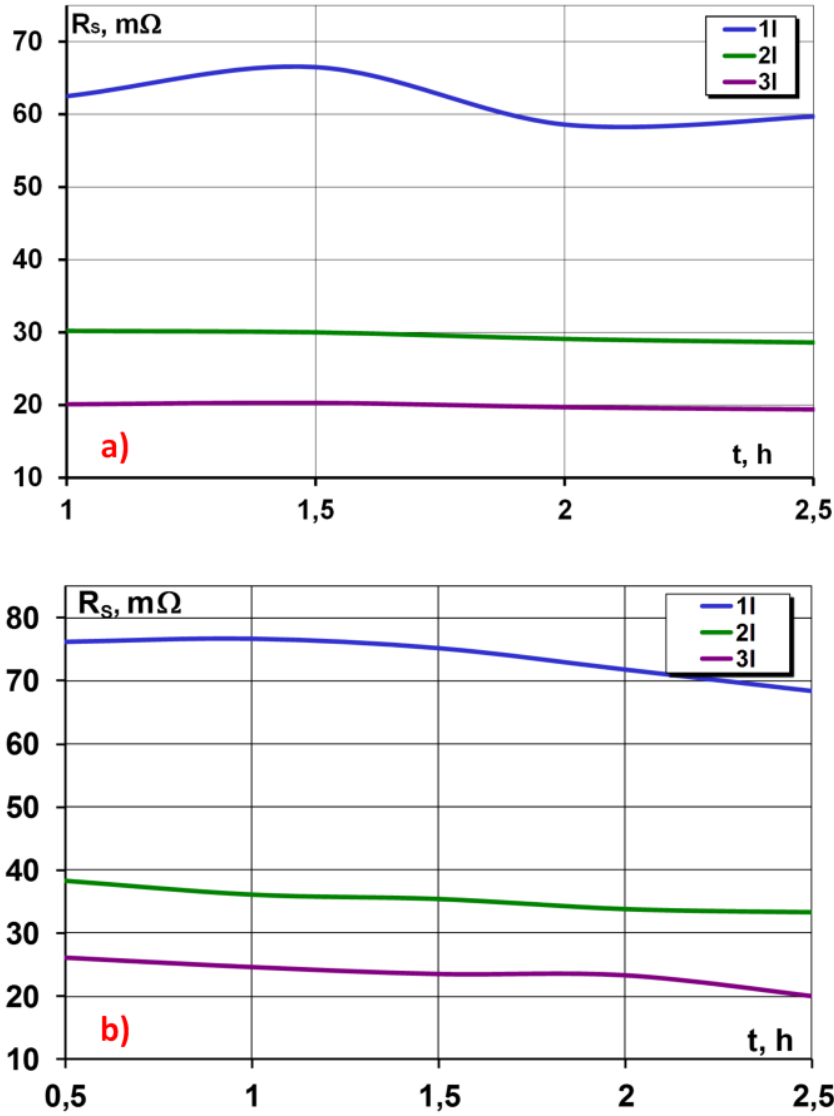

Fig. 5. Sheet resistance dependence on the sintering time (a: PI - sheet B; b: PI - sheet A) for 1-, 2-, 3-layer paths printed with NPS-J ink

the time in reported cases has a weak influence on the change of the paths resistance.

A much greater influence on the resistance has the temperature. In some cases, defects (especially in the first printed layer) and microcracks formed during the printing and sintering process, respectively, have also a quite significant influence on the path resistance.

\section{PRACTICAL VERIFICATION}

The studies presented in Sections III and IV and devoted to very simple patterns in the form of the paths were carried out to get to know the properties of such patterns and elaborate effective treatment procedures for the layer functionalization processes of the inkjet printing technology. In practice, more complex patterns are usually printed. In this section an example of such pattern is presented. A HF antenna of a semi-passive RFID transponder (Fig. 6) was printed and investigated. The antenna pattern consist of six coils accomplished as paths with the design width of $0.6 \mathrm{~mm}$. Some details of the technological process for this antenna are presented in [2]. The antenna was printed on the untreated PI substrate by the use of the NPS-J ink and a single nozzle. The 3-layer paths were printed with the resolution of $400 \mathrm{dpi}$ and the single drop ejection volume of about $33 \mathrm{pL}$. The antenna was sintered at a temperature of $220^{\circ} \mathrm{C}$ for a time of 1 hour. The average path width measured after the sintering process is $0.73 \mathrm{~mm}$ and corresponds with the results presented in Section IV for the 3-layer paths. 


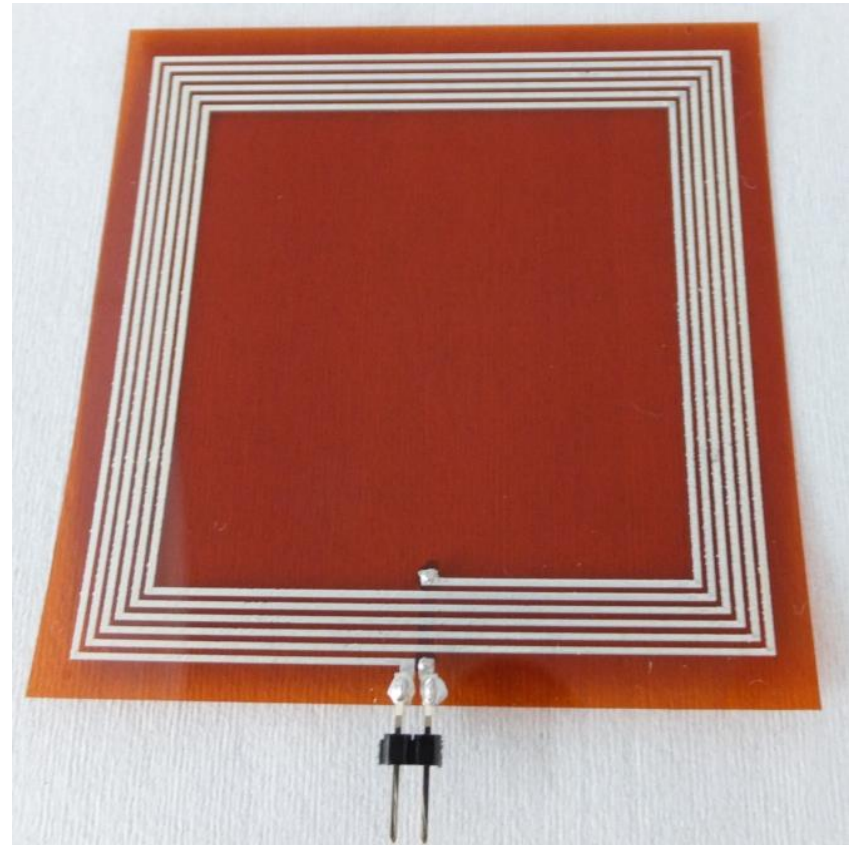

Fig. 6. HF antenna for semi-passive RFID transponder
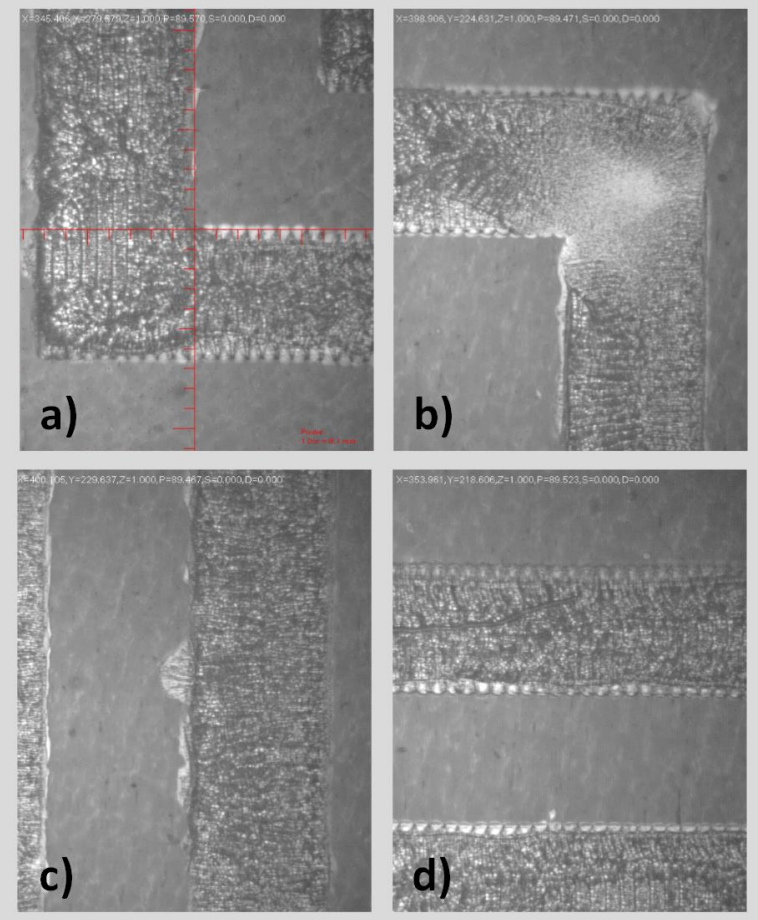

Fig. 7. Inspected paths of printed antenna: left (a) and right (b) corner, horizontal (c) and vertical (d) paths

The printed paths are relatively regular (Fig. 7a, b), but in some places local widenings formed in the first path layer can be found (Fig. 7c). In some subareas of the paths longwise cracks can be observed (Fig. 7d). However, the mentioned defects does not have a significant influence on the path resistance. The DC resistance of the whole path measured using the four-wire method is $23 \Omega$. The sheet resistance calculated according to Eq. (1) is $12 \mathrm{~m} \Omega$. For the path length and width of $1383 \mathrm{~mm}$ and $0.73 \mathrm{~mm}$, respectively. It should be noted that the obtained result is about twice smaller than for the 3-layer paths described in Section IV (Fig. 4a, b). The reason of this relation is a thicker layer of silver (the ejected drop volume was bigger by about 1/3) and a smaller number of defects in the printed layers (mainly in the first one).

\section{CONCLUSION}

In this work the influence of sintering conditions on the inkjet printed paths resistance was presented. The investigated patterns were printed with two nanoparticle inks (NPS-J and NPS-JL) on two kinds of flexible substrates (polyimide and polyethylene terephthalate). The patterns were sintered by the thermal treatment at different temperatures and for different times and their basic properties like the resistance, geometry etc. were investigated.

In case of the NPS-JL ink printed on the PET substrate, achieving a relatively small resistance of printed patterns (for examples the HF RFID antenna circuit) is possible for the sintering temperature of $160^{\circ} \mathrm{C}$. This temperature can be increased up to $180^{\circ} \mathrm{C}$ if still a lower resistance is needed. However, the thermal stresses can create cracks and damage the metallic layer.

In case of the NPS-J ink printed on the PI substrate, the sintering temperature of $240^{\circ} \mathrm{C}$ can be assumed as the optimal one. The increase of this temperature up to $260^{\circ} \mathrm{C}$ does not give distinct profits but it can lead to the occurrence of cracks. For the temperature of $280^{\circ} \mathrm{C}$ the cracks dimensions are large enough to cause an increase of the resistance.

The obtained results show that the sintering temperature is the main factor affecting the resistance of paths made on polymer substrates using the inkjet printing technology with a conventional ink in the form of a suspension of silver nanoparticles. The sintering temperature can influence the resistance of printed patterns in a wide range. This resistance is less sensitive to the sintering time and the time of about $1 \mathrm{~h}$ can be assumed as a sufficient time for the thermal treatment process, for both types of the tested inks. As shown in Fig. 4, in most cases, increasing the sintering temperature leads to decreasing the paths resistance. In some cases, especially when the metallic layer is too thick, an increase of the temperature leads to an increase of the resistance due to microcracks of the paths. The obtained results show also that the printed patterns should have at least two layers because the probability of occurrence of defects and the resistance decrease when the number of layers increases. However, increasing the number of layers above 3 worsens the mechanical properties of patterns.

If the geometry of sintered patterns should be very accurate, it is worth taking into account the shrinkage of substrate which increases with the sintering temperature and depends on the substrate material. The number and rate of cracks can be diminished by the preliminary material ageing process.

\section{REFERENCES}

[1] M. Jakubowska, Techniki drukarskie w elektronice. Materiały i technologie, Oficyna Wydawnicza Politechniki Warszawskiej, Warszawa, 2013 (in Polish)

[2] P. Jankowski Mihułowicz, G. Tomaszewski, M. Węglarski, Flexible antenna design for semi-passive HF RFID transponder in ink-jet technology, Przegląd Elektrotechniczny (Electrical Review), No. 4, 2015, pp. 1-5, doi: 10.15199/48.2015.04.01.

[3] P. Jankowski-Mihułowicz, W. Kalita, M. Skoczylas, M. Węglarski, Modelling and Design of HF RFID Passive Transponders with Additional 
Energy Harvester, International Journal of Antennas and Propagation, vol. 2013, 2013, pp. 1-10, doi:10.1155/2013/242840.

[4] Z. Stempien, E. Rybicki, T. Rybicki, J. Lesnikowski, Inkjet-printing deposition of silver electro-conductive layers on textile substrates at low sintering temperature by using an aqueous silver ions-containing ink for textronic applications, Sensors and Actuators B: Chemical, vol. 224, pp. 714-725, 2016, doi:10.1016/j.snb.2015.10.074

[5] E. Sowade, F. Göthel, R. Zichner, and R. R. Baumann, Inkjet printing of UHF antennas on corrugated cardboards for packaging applications, Applied Surface Science, vol. 332, pp. 500-506, 2015, doi:10.1016/j.apsusc.2015.01.113.

[6] J. Felba, H. Schaefer, Materials and Technology for Conductive Microstructures, Nanopackaging: Nanotechnologies and Electronics Packaging (ed. J. E. Morris), Springer, 2008, pp. 239-263, doi 10.1007/978-0-387-47325-3 5 .

[7] W. Zhang, E. Bi, M. Li, and L. Gao, Synthesis of Ag/RGO composite as effective conductive ink filler for flexible inkjet printing electronics, Colloids and Surfaces A: Physicochemical and Engineering Aspects, vol. 490, pp. 232-240, 2016, doi:10.1016/j.colsurfa.2015.11.014.

[8] A. Kamyshny, J. Steinke, S. Magdassi, Metal-based Inkjet Inks for Printed Electronics, The Open Applied Physics Journal, vol. 4, 2011, pp. 19-36, doi: 10.2174/1874183501104010019.

[9] J. Felba, K. Nitsch, T. Piasecki, S. Tesarski, A. Mościcki, A. Kinart, D. Bonfert, K. Bock, Properties of conductive microstructures containing nano sized silver particles, 11th Electronics Packaging Technology Conference, EPTC '09, Singapore, 9-11.12.2009, pp. 879-883, doi: 10.1109/EPTC.2009.5416421

[10] T. Fałat, B. Płatek, J. Felba, Sintering process of silver nanoparticles in ink-jet printed conductive microstructures - Molecular dynamics approach, 13th International Conference on Thermal, Mechanical and Multi-Physics Simulation and Experiments in Microelectronics and Microsystems (EuroSimE), 16-18.04.2012, pp. 1-5, doi:10.1109/ESimE.2012.6191782.
[11] M. Puchalski, P. J. Kowalczyk, Z. Klusek, W. Olejniczak, The Applicability of Global and Surface Sensitive Techniques to Characterization of Silver Nanoparticles for Ink-Jet Printing Technology, Nanotechnology and Nanomaterials: Silver Nanoparticles (ed. David Pozo Perez), InTech, 2010, pp. 63-78, doi: 10.5772/8507.

[12] J.Felba, A. Mościcki, Wykorzystanie druku strumieniowego do tworzenia mikrostruktur przewodzących elektrycznie (Electrically conductive microstructures made by ink-jet printing technology), Drukowana elektronika w Polsce (ed. M. Jakubowska, J. Sitek), Monografia Instytutu Tele- i Radiotechnicznego, Warszawa, 2010 (in Polish).

[13] Amepox Microelectronics, Nano Ink AX JP-60n Low Temerature Conductive Ink for Jet Printing, datasheet (downloaded from the manufacturer site), 05.2014).

[14] Harima Chemicals Group, NanoPaste series, Concept \& Electronic Materials, datasheet (downloaded from the manufacturer site), 12.2013, pp. 20-21.

[15] V. Zardetto, T. M. Brown, A. Reale, A. Di Carlo, Substrates for flexible electronics: A practical investigation on the electrical, film flexibility, optical, temperature, and solvent resistance properties, Polymer Physics, vol. 49, Issue 9, 2011, pp. 638-648, doi: 10.1002/polb.22227.

[16] J. Niittynen, R. Abbel, M. Mäntysalo, J. Perelaer, U. S. Schubert, and D. Lupo, Alternative sintering methods compared to conventional thermal sintering for inkjet printed silver nanoparticle ink, Thin Solid Films, vol. 556, pp. 452-459, 2014, doi: 10.1016/j.tsf.2014.02.001

[17] I. Theodorakos, F. Zacharatos, R. Geremia, D. Karnakis, and I. Zergioti, Selective laser sintering of $\mathrm{Ag}$ nanoparticles ink for applications in flexible electronics, Applied Surface Science, vol. 336, pp. 157-162, 2015, doi: 10.1016/j.apsusc.2014.10.120.

[18] G. Tomaszewski, J. Potencki, T. Wałach. M. Pilecki, Investigation of ink spreading on various substrates in inkjet technology, Elektronika, ISSN 0033-2089, vol. 3, 2015, pp. 259-274, doi: 10.15199/13.2015.3.6. 